\title{
VARIAÇÕES NAS ROTINAS DE UM INSTITUTO DE TECNOLOGIA E INOVAÇÃO: ADAPTAÇÕES AO CONTEXTO E (RE)ALINHAMENTO DE INTERESSES
}

Changes on organizational routines on a Technology and Innovation Institute: suit to context and interests (re)alignment

Florence Vidal Perfeito

E-mail: florencevidal@gmail.com Mestre em Administração pela Pontifícia Universidade Católica do Rio de Janeiro, com ênfase em Organizações; Pós-graduada em Gestão de Negócios com foco em Sustentabilidade pela Universidade Federal Fluminense, com vivência internacional na Braunschweig University of

Technologye, na Alemanha. https://orcid.org/0000-0002-2360-2069

Samantha Luiza de Souza Broman

E-mail: sambroman@hotmail.com Mestre e Doutoranda em Administração de Empresas pela Pontifícia Universidade Católica do Rio de Janeiro. Endereço para contato: Rua Marquês de São Vicente, 225, 22451-045, Gávea, Rio de Janeiro, Brasil. https://orcid.org/0000-0001-5239-8629

\section{Sandra Regina da Rocha-Pinto}

E-mail: sanpin@iag.puc-rio.br Doutora em Educação pela Pontifícia Universidade Católica do Rio de Janeiro; Mestre em Administração de Empresas pela Pontifícia Universidade Católica do Rio de Janeiro; Professora no Departamento de Administração de Empresas da Pontifícia Universidade Católica do Rio de 


\section{Resumo}

Neste trabalho pesquisaram-se as razões para variações nas rotinas organizacionais de compras de insumos químicos em um Instituto de Tecnologia e Inovação do Rio de Janeiro. Os dados coletados basearam-se em entrevistas com 18 pessoas, na análise de mais de 30 documentos, e em observações empíricas, no período entre agosto de 2015 e janeiro de 2016. Os resultados encontrados sugerem falta de integração, assim como o desalinhamento de interesses e de interpretações entre as áreas envolvidas: são mantidas formas de desempenhar rotinas organizacionais com estruturas, artefatos e fundamentos que podem estar inadequados ao contexto de compras de insumos químicos, que são utilizados em rotinas de análises e ensaios. Logo, apesar de ter havido a criação de novos padrões de ação mais adaptados ao contexto, que podem propiciar mais agilidade para as rotinas de compra, corroborando com a ideia do potencial generativo e da flexibilidade nas rotinas organizacionais preconizada pela teoria (Pentland \& Feldman, 2005; Feldman, 2016), é possível observar que o andamento para a estabilização da nova rotina pode carecer de manifestações de trégua que possibilitem a revisão do uso dos artefatos nas rotinas. No presente trabalho também foram reveladas quatro categorias sobre os fatores motivadores das variações nas rotinas de compras, colaborando, assim, para o campo de estudo da Dinâmica das Rotinas (Routine Dynamics) e da ecologia das rotinas (Feldman, 2016; Howard-Grenville \& Rerup, 2017), e, também, para o entendimento sobre o papel dos artefatos nas interações entre rotinas interdependentes e sobre a Trégua (Truce).

Palavras-chave: Rotinas organizacionais. Padrões de ação. Processos institucionais.

\section{Abstract}

This research sought to understand the motives driving the variations in organizational routines, within the context of chemical procurement for a Technology and Innovation Institute in Rio de Janeiro. This case study was based on 18 interviews and the analysis of more than 30 documents and empirical observations, in the period between August 24, 2015 and January 29, 2016. The results suggest a lack of integration and a misalignment of the interests and interpretations between the areas, thus incentivizing maintaining routines with structures, artifacts and bases inadequate for the context of chemical procurement, which are used in analysis and testing routines. Therefore, despite the creation of new standards of action that are better adapted to the context and can provide streamlining of procurement routines, consistent with the idea of flexibility of organizational routines advocated by the theory (Pentland \& Feldman, 2005; Feldman, 2016), it is possible to observe that the progress towards the stabilization of the new routine may lack manifestations of truce that allow the revision of the use of the artifacts in the routines. The present work also revealed four categories on the motivating factors of the variations in the procurement routine, thus collaborating for the field of study of the Routine Dynamics and routines ecology (Feldman, 2016; Howard-Grenville \& Rerup, 2017), with the understanding of the role of artifacts in the interactions between interdependent routines and about the Truce.

Keywords: Organizational routines. Patterns of action. Institutional processes.

\section{INTRODUÇÃO}

As rotinas organizacionais (ROs) são unidades fundamentais para o desempenho de um negócio, uma vez que carregam consigo o poder de transformação (Feldman, 2004). Assim, 
sua gestão se constitui uma função organizacional crítica. O tema das rotinas organizacionais é pertinente para o ambiente empresarial atual, bem como tem seu espaço em publicações de ponta do campo da administração (Nascimento, Ruas, \& Silva, 2017).

As rotinas vinham sendo estudadas como "entidades", sem considerar as suas partes constituintes (Howard-Grenville \& Rerup, 2017). Mas uma nova abordagem, atribuída aos autores Martha Feldman e Brian Pentland (em estudos conjuntos e separados), adota o foco na dinâmica interna das rotinas e em seus padrões de ação. Nessa perspectiva as ROs são teorizadas a partir da recursividade entre seus aspectos performativo e ostensivo. Vistas assim, possuem um potencial de flexibilidade endógeno, que as relaciona tanto com a estabilidade quanto com a mudança. Dessa perspectiva, decorrem os estudos sobre a Dinâmica das Rotinas (Routine Dynamics) (Feldman, 2016). Há, também, um interesse em estudos sobre as inter-relações e interdependência (rotinas múltiplas), tendo em vista que as rotinas ocorrem em "ecologia" (Feldman, Pentland, D'Adderio, \& Lazaric, 2016).

Com o objetivo de apresentar contribuições teóricas e implicações práticas a respeito da dinâmica interna de rotinas interdependentes, bem como sobre o papel dos artefatos nessa dinâmica, neste artigo detalha-se a investigação empírica das rotinas organizacionais de compras de insumos químicos em um Instituto de Tecnologia e Inovação que realiza serviços de análises e ensaios. Considerando-se que esse Instituto sofre pressão do mercado tanto por redução de custos quanto por aumento dos níveis de serviço, julgou-se relevante avaliar as rotinas organizacionais de compra de insumos químicos, na medida em que são essenciais para o desempenho das rotinas subsequentes de análises e ensaio. Para tanto, formulou-se a seguinte questão de pesquisa: como o papel dos artefatos e dos atores envolvidos influenciam a dinâmica das rotinas organizacionais e suas relações de interdependência?

Para responder a essa questão, este trabalho buscou-se revelar a importância da sinergia entre diferentes áreas que compartilham rotinas interdependentes, assim como analisar a questão da trégua nessas rotinas interligadas (Howard-Grenville \& Rerup, 2017; Feldman, 2016; Pentland \& Feldman, 2005; Nelson \& Winter, 1982), tendo em vista que, segundo Zbaracki e Bergen (2010), a interdependência também pode trazer à tona ostensivos distintos e conflitos.

Análise do caso estudado identificou que, apesar de a variação da rotina de compras de insumos ter proporcionado produtividade e agilidade para atender à demanda, a situação atual da rotina adaptada ainda não se encontra adequada para se estabilizar. Desse modo, é possível notar que os artefatos compartilhados por essas rotinas interdependentes ainda carecem de revisões e atualizações, até que se alcance uma situação que revele manifestações de trégua para que um novo padrão de ação se estabilize. No caso estudado, as áreas envolvidas nas rotinas interligadas apresentam aspectos ostensivos contraditórios, sem que seja percebida alguma forma de trégua entre elas que propicie a modificação dos artefatos (Cacciatori, 2012) e/ou nova variação da rotina.

Tendo em vista o crescente interesse pelo tema da Dinâmica das Rotinas Organizacionais (Howard-Grenville \& Rerup, 2017) e pelo tema da trégua em rotinas interdependentes (Salvato \& Rerup, 2017; Zbaracki \& Bergen, 2010; Howard-Grenville \& Rerup, 2017), sob a perspectiva processual da dinâmica das rotinas, os achados desta pesquisa podem contribuir com a noção de que a 
estabilização de modificações em rotinas interdependentes (e a adequação de artefatos) depende que se identifiquem as manifestações de trégua não apenas "dentro" da rotina, mas também "entre" rotinas. Desse modo, a estabilização da rotina poderia ser idenfificada por meio do que é considerado no presente trabalho por "manifestações de trégua": uma "confiança mútua" entre os grupos (Zbaracki \& Bergen, 2010), "uma vontade de fazer concessões", colaboração mútua e uma cessão de disputas para evitar que a execução das rotinas siga interesses divergentes (Salvato \& Rerup, 2017), assim como mudanças de fatores cognitivos e motivacionais (Kaplan, 2015).

As categorias identificadas nesta pesquisa visam explicar fatores motivadores das variações nas rotinas de compras de insumos químicos para análises e ensaios. Além disso, ilustram como o novo padrão de ação que emergiv em meio a aspectos ostensivos contraditórios ainda demanda continuidade em suas modificações; busca por alguma forma de trégua entre os envolvidos; e reconhecimento por parte de demais áreas da organização (como Auditoria e área de Processos). As categorias identificadas são: compreensão de papéis e interesses; papel dos artefatos; relação entre os aspectos ostensivo, performativo e artefatos; e fatores contingenciais na dinâmica das rotinas organizacionais.

Este estudo segue em cinco partes, em que a primeira introduz o problema de pesquisa, os objetivos, e a relevância e delimitação; a segunda apresenta as teorias; a terceira aborda o método; a quarta apresenta a discussão dos resultados; e a quinta traz as considerações finais da pesquisa, limitações e recomendações futuras.

\section{FUNDAMENTAÇÃO TEÓRICA}

Para realizar a discussão teórica com o objetivo de entender as relações e influências mútuas entre as rotinas de compra de insumos químicos e as rotinas de análise e ensaios, estruturou-se o referencial teórico em três tópicos: Conceito e Aspectos Constitutivos das Rotinas Organizacionais; Artefatos; e Relação Dinâmica e Variação das Rotinas Organizacionais.

\subsection{CONCEITO E ASPECTOS CONSTITUTIVOS DAS ROTINAS ORGANIZACIONAIS}

As ROs formam a estrutura para as ações da empresa, exercendo o papel de coordenação, apresentando sequência e uniformidade (Dosi, Nelson, \& Winter, 2000), auxiliando o gerenciamento da empresa e trazendo coerência às suas ações (Nelson \& Winter, 1982). Além disso, as ROs podem atenuar e minimizar conflitos em situações nas quais os atores agem de acordo com seus interesses, valores, habilidades, hábitos e reflexos (Nelson \& Winter, 1982). Nessa perspectiva, as ROs visam à redução da incerteza: as pessoas se adaptam e imitam comportamentos para buscar o sucesso, com base na tentativa e erro, podendo criar rotinas para resolver problemas (Feldman, 2003; Rerup \& Feldman, 2011).

Feldman e Pentland (2003) definem rotinas organizacionais como "[. . .] padrões repetitivos e reconhecíveis de ações interdependentes realizadas por vários atores" (p. 95). A repetitividade 
se refere àquilo que é contínuo, regular ou igual, exemplificada por atividades feitas e refeitas inúmeras vezes da mesma forma (Pentland \& Haerem, 2015). Becker (2005) discorre sobre a conceituação de Pentland (2003) sobre a variação sequencial nas rotinas, com destaque para questões comportamentais, esclarecendo que "[. . .] a variedade sequencial se refere à variedade de diferentes combinações de etapas do processo para atingir o mesmo objetivo" (p. 822).

Dois aspectos são constitutivos das ROs: aspecto ostensivo e aspecto performativo. $O$ aspecto ostensivo é o conhecimento abstrato de tudo o que deve ser realizado pelos participantes, e o aspecto performativo refere-se à execução da rotina por pessoas específicas, em horários específicos, em locais específicos. Sem esses dois aspectos, a rotina não pode existir (Pentland \& Feldman, 2005; Parmigiani \& Howard-Grenville, 2011). Os autores ressaltam que os aspectos ostensivo e performativo podem ser ativados por artefatos que servem como identificadores (scripts) dos aspectos da rotina. Desse modo, existem atores não humanos nas rotinas - artefatos -, como computadores ou robôs para a realização de partes de uma rotina (Pentland \& Feldman, 2005).

O aspecto ostensivo não é visível. Diferentes pessoas podem ter entendimentos diferentes sobre uma mesma tarefa. O ostensivo pode ser formado por meio de suposições tácitas que devem fazer sentido, ou mesmo um conjunto de sobreposições e relatos parciais, assim como representar a narrativa da rotina pelos participantes. Ademais, há uma armadilha do aspecto ostensivo, dada a tendência de as pessoas confundirem-no com o conceito de rotina (Pentland \& Feldman, 2005, 2008b). Além disso, é possível verificar a ação clara de um componente tácito, implícito na rotina e que depende do ponto de vista do participante (Miller, Pentland, \& Choi, 2012).

Por sua vez, o aspecto performativo indica a performance de ações específicas, realizadas por pessoas específicas (Pentland \& Feldman, 2005). No momento de performar uma rotina, é possível tomar ações ou usar mecanismos que a deixam igual às demais, gerando estabilidade, ou usar mecanismos que façam com que a performance se torne diferente, gerando mudança, revelando o poder da agência de seus participantes (Feldman \& Pentland, 2003). Esse fato permite a criação, atualização e manutenção dos artefatos a partir das ações performadas pelos sujeitos, que envolvem uma série de comportamentos, pensamentos e sentimentos (Feldman, 2000). A recursividade entre os aspectos ostensivo, performativo e os artefatos na rotina a torna uma fonte de mudança (Pentland \& Feldman, 2005).

Acredita-se ser oportuno observar a definição de Cherman e Rocha-Pinto (2016) a respeito da "rotina traduzida" para ilustrar a flexibilidade relacionada com o contexto em que uma determinada rotina organizacional se encontra, destacando o lado formal dessa "tradução" para seguir as regras predeterminadas e a questão situacional em que "[. . . ] determinadas tarefas não se aplicam ou deixam de fazer sentido com o tempo" (p. 428), de forma que a própria rotina é revista.

Assim, estudos sobre as rotinas organizacionais na perspectiva processual abrem a "caixapreta" das rotinas para analisar as partes internas das rotinas e as interações entre seus aspectos ostensivo e performativo, considerando também os artefatos (Pentland \& Feldman, 2005, 2008b; Parmigiani \& Howard-Grenville, 2011; Howard-Grenville \& Rerup, 2017). 


\subsection{ARTEFATOS}

Os artefatos são usados para tentar garantir a reprodução de padrões de ação particulares (Pentland \& Feldman, 2008a), embora haja uma tendência para a confusão entre artefatos e o aspecto ostensivo. Nesse sentido, Howard-Grenville e Rerup (2017) alertam para que não se confunda o aspecto ostensivo com os artefatos escritos (como os padrões operacionais Standart Operatitional Procedures (SOP)), uma vez que o primeiro se refere ao ideal da rotina e é abstrato. Os artefatos devem ser tratados como indicadores subjacentes aos aspectos ostensivo e performativo, porém, podem não apontar os procedimentos necessários para o desempenho de uma rotina por estarem incompletos, desatualizados, ambíguos ou mesmo não indicarem a lógica correta que guia a ação (Pentland \& Feldman, 2008a).

A produção de um arcabouço de instrumentos diversos não deve desconsiderar a característica generativa da rotina organizacional, que deve coordenar as ações de múltiplos atores (Pentland \& Haerem, 2015; Pentland \& Feldman, 2008b). As variações entre os artefatos e as performances em ambientes de grande controle podem indicar a desatualização ou a desatenção na criação do artefato e podem causar uma desconexão entre metas e resultados (Pentland \& Feldman, 2005, 2008a).

Portanto, artefatos podem e são intencionalmente modificados diante de situações de incertezas do ambiente. Assim, Cacciatori (2012) alega que o sucesso na "[. . .] criação de um sistema de artefatos para endereçar as demandas de resolução de problemas depende que seja feito de maneira que seja considerada aceitável, ao mesmo tempo em que apoie uma divisão de trabalho que constitua uma trégua aceitável" (p. 1579).

\subsection{A RELAÇÃO DINÂMICA E VARIAÇÃO DAS ROTINAS ORGANIZACIONAIS E SUA ECOLOGIA}

Com a intenção de explicar como as empresas ficam estáveis, mudam ou sobrevivem nos mercados, Feldman e Pentland (2003) desafiaram a compreensão tradicional de rotinas organizacionais como criadoras de inércia na empresa, atribuída aos autores Cyert e March na década de 1960. A definição original é complementada com a noção de que as rotinas organizacionais são sistemas generativos que podem produzir variedades de performances, dependendo das circunstâncias sociais e materiais (Feldman \& Pentland, 2008; Pentland \& Harem, 2015). Nessa perspectiva, entender a relação dinâmica da rotina é fundamental para a sua gestão, alteração ou manutenção (Feldman \& Pentland, 2003), valorizando o papel da agência como ingrediente originador da capacidade endógena de promover a mudança (Pentland \& Feldman, 2005).

O relacionamento entre as performances e os artefatos atrelados às rotinas encobre as relações de poder dentro das organizações, por meio do controle de comportamentos. Se existem regras é porque elas devem ser cumpridas e sua adoção é uma medida de controle. Onde há 
muito controle, grandes variações apontam para desentendimentos em relação ao trabalho a ser desempenhado ou resistência aos artefatos (Pentland \& Feldman, 2005).

Além disso, Feldman e Pentland (2003) sugerem que o contexto da organização pode restringir e até impedir a flexibilização da rotina (Howard-Grenville, 2005; Parmigiani \& HowardGrenville, 2011) a ponto de as pessoas poderem sofrer pressões para manter a consistência nas rotinas, ainda que haja a mudança nos padrões (Turner \& Rinova, 2012).

No que diz respeito à relação de interdependência entre as rotinas organizacionais, é possível concordar com Howard-Grenville, Rerup, Langley, e Tsoukas (2016), que não há um vácuo entre as rotinas, assim como as ações, artefatos ou pessoas podem estar relacionados a uma rotina e/ou a outras rotinas concomitantemente. Assim, Feldman et al. (2016) sugerem uma agenda de pesquisa sobre a "ecologia" das rotinas, em termos de como essa interação entre diferentes rotinas pode contribuir para o estudo da dinâmica das rotinas. Paralelamente, Spee, Jarzabkowski, e Smets (2016) apontam que a literatura ainda carece de estudos sobre a interdependência entre rotinas, com foco na complementaridade entre a padronização e a flexibilidade e em como conflitos são minimizados.

Assim, entende-se que há interesse atual em avançar os estudos que abordem a gerência de conflitos implícitos (e/ou explícitos) a partir da ótica da dinâmica interna de rotinas interdependentes, buscando entendimentos sobre a Trégua (Truce) na perspectiva processual. Esse categoria de análise foi originalmente tratada por Nelson e Winter (1982) no conceito de "a rotina como trégua"; os conflitos ficavam subjacentes em razão do não interesse dos indivíduos em romper com o valioso "estado de trégua". As publicações subsequentes sobre a trégua concordam que os conflitos não são de fato "eliminados" (Nelson \& Winter, 2002; Salvato \& Rerup, 2017; Zbaracki \& Bergen, 2010; Pentland \& Feldman, 2005), e avançam em melhor compreendê-la e conceituá-la. Desse modo, Salvato e Rerup (2017) esclarecem que "[. . .] a trégua reflete um acordo de cessar as lutas ou disputas por um período de tempo. Quando observada na rotina em performance, a trégua é um acordo implícito entre os participantes da rotina para executar a tarefa da rotina" (p. 2). Os autores ainda completam que, com a trégua, evita-se que as rotinas sejam conduzidas por interesses divergentes.

Portanto, é possivel observar na corrente que estuda as dinâmicas internas das rotinas o crescimento do interesse para que se investigue sobre a interdependência entre rotinas, como se afetam mutuamente (Howard-Grenville et al., 2016; Feldman et al., 2016; Sele \& Grand, 2016; Zbaracki \& Bergan, 2010; Spee, Jarzabkowski \& Smets, 2016) e como podem ser mais ou menos generativas (Sele \& Grand, 2016). Dessa forma, cabe estudar como ocorrem as tréguas (Truce) "entre" rotinas, sob a perspectiva processual (Kremser \& Schreyögg, 2016; Salvato \& Rerup, 2017; Zbaracki \& Bergen, 2010; Howard-Grenville \& Rerup, 2017) e como essa "trégua" sustenta a tensão entre ostensivos contraditórios (Howard-Grenville \& Rerup, 2017).

A visão baseada na prática (Feldman \& Orlikowski, 2011) com foco na "ação" embutida nas padronizações, com uma abordagem processual e não estática (Feldman, 2016) foi priorizada nesta pesquisa. Explorou-se o fato de que, segundo Kremser e Schreyögg (2016), as rotinas compõem sistemas interligados. 


\section{METODOLOGIA DA PESQUISA}

\subsection{TIPO DE PESQUISA - FINS E MEIOS}

No que diz respeito à finalidade com esta pesquisa, pretendeu-se investigar as rotinas de compra de insumos químicos em um Instituto de Tecnologia e Inovação do Rio de Janeiro a fim de entender os fatores que motivam suas variações. Quanto aos meios, este estudo possui natureza qualitativa e buscou-se explorar um estudo de caso único, com uso de múltiplas fontes de dados. O rigor na condução desta pesquisa foi reverenciado no uso de um conjunto de evidências, considerando a subjetividade natural do método (Yin, 2003). Conforme os preceitos sugeridos por Pentland e Feldman (2005) e Turner e Rindova (2012), realizou-se a investigação das rotinas de compra por meio de entrevistas com pessoas dos níveis estratégico, tático e operacional, com vistas a captar múltiplas visões dos aspectos da rotina. A Tabela 1 apresenta o perfil dos participantes das entrevistas:

Tabela 1

Resumo dos participantes das entrevistas

\begin{tabular}{|c|c|c|c|c|c|}
\hline Cód. & Área & Ator & $\begin{array}{c}\text { Nível } \\
\text { hierárquico }\end{array}$ & Experiência na área & $\begin{array}{c}\text { Duração da } \\
\text { entrevista }\end{array}$ \\
\hline $\mathrm{Cl}$ & \multirow{8}{*}{ Compras } & Gerente-geral de Compras & Estratégico & 29 anos & 58 \\
\hline C2 & & Gerente de Compras & Estratégico & 26 anos & $54^{\prime}$ \\
\hline C3 & & Chefe do Setor de Compras & Tático & 10 anos & $50^{\prime}$ \\
\hline $\mathrm{C} 4$ & & $\begin{array}{l}\text { Chefe do Setor do Planejamento e Cadas- } \\
\text { tro de Materiais }\end{array}$ & Tático & 2,5 anos & $47^{\prime}$ \\
\hline C5 & & Coordenador do Centro de Distribuição & Tático & 4,5 anos & Ih e 18' \\
\hline C6 & & Almoxarife & Operacional & 9 anos & $34^{\prime}$ \\
\hline C7 & & Compradora 1 & Operacional & 2,5 anos & $42^{\prime}$ \\
\hline $\mathrm{C} 8$ & & Compradora 2 & Operacional & 1 ano & $46^{\prime}$ \\
\hline P1 & \multirow[t]{4}{*}{ Processos } & $\begin{array}{l}\text { Gerente de Processos } \\
\text { Especialista em Processos }\end{array}$ & $\begin{array}{l}\text { Estratégico } \\
\text { Tático }\end{array}$ & $\begin{array}{l}4 \text { anos } \\
4 \text { anos }\end{array}$ & $44^{\prime}$ \\
\hline $\mathrm{T} 1$ & & Gerente do "Instituto A" & Estratégico & 7 anos & $38^{\prime}$ \\
\hline $\mathrm{T} 2$ & & Chefe do Setor de Metrologia & Estratégico & 1,5 anos & $51^{\prime}$ \\
\hline Т3 & & Chefe Administrativo Financeiro & Tático & 5 anos & $56^{\prime}$ \\
\hline T4 & \multirow{5}{*}{ "Instituto A" } & Especialista de Laboratório 1 & Tático & 8 anos & $25^{\prime}$ \\
\hline T5 & & Especialista de Laboratório 2 & Tático & 1 anos & $36^{\prime}$ \\
\hline T6 & & Analista Técnico de Laboratório & Operacional & 6 anos & $25^{\prime}$ \\
\hline T7 & & Assistente Administrativa 1 & Operacional & 6 anos & $28^{\prime}$ \\
\hline T8 & & Assistente Administrativa 2 & Operacional & 8 anos & $13^{\prime}$ \\
\hline
\end{tabular}

Também foram realizadas observações empíricas, assim como de pesquisa documental nos artefatos existentes na empresa, descritas na Tabela 2. As observações visaram tanto a perspectiva processual do desempenho da rotina quanto a evidência da existência de significados diferentes na situação. O que viabilizou essas observações foi o fato de as entrevistas terem ocorrido no próprio ambiente de trabalho, no cotidiano de compras, quando foram feitas anotações sobre aspectos não verbalizados pelos entrevistados, assim como sobre a aparência geral do ambiente 
de trabalho, úteis para enriquecer a análise. Os artefatos atrelados às rotinas estudadas também foram apresentados para uma das pesquisadoras, durante as entrevistas.

Ademais, a combinação de diferentes fontes e de perfis dos sujeitos entrevistados pretendeu atender à preconização de Remenyi, Williams, Money, e Swartz (1998): múltiplas formas de evidências em um estudo de caso corroboram como uma triangulação que torna o estudo mais convincente.

No presente trabalho, a unidade de análise é denominada Instituto " $A$ " para preservar sua identidade. A rotina de compras é desempenhada pela equipe de compras (integrante da área de apoio de suprimentos), equanto a área técnica atua na rotina de análises e ensaios, que utiliza insumos químicos em suas atividades.

Três fatos motivaram a presente investigação: identificação, por meio de um mapeamento de problemas da operação, em que a maioria das compras de insumos químicos é realizada pela equipe técnica que os utiliza em suas atividades de análises e ensaios; uma auditoria detectou uma não conformidade de descumprimento dos prazos de compra; e há uma solicitação demasiada do gestor de laboratórios para aprovações especiais para a compra de insumos químicos.

Cabe ressaltar que o primeiro fato motivador citado da presente investigação (a inversão da área que pratica a maioria das compras dos insumos químicos) sugeriu a existência da variação no padrão de ação que impacta mutuamente essas rotinas interdependentes (de compras e de análise, e ensaios), sinalizando a oportunidade de se estudar a dinâmica das rotinas em sua ecologia (Feldman et al., 2016). Os dois outros fatores motivadores reforçaram as "pistas" sobre aspectos ostensivos conflitantes entre os particantes das rotinas, revelando uma oportunidade de se estudar a trégua nessa dinâmica em rotinas múltiplas (Howard-Grenville \& Rerup, 2017; Sele \& Grand, 2016).

A coleta de dados ocorreu no período entre 24 de agosto de 2015 e 29 de janeiro de 2016. As entrevistas individuais foram realizadas entre os dias 07 e 18 de dezembro de 2015, a partir de um roteiro semiestruturado e gravadas com o consentimento dos entrevistados. Os dados coletados basearam-se em entrevistas com 18 pessoas, na análise de mais de 30 documentos e em observações empíricas. As transcrições de mais de 12 horas de gravação geraram 84 páginas de conteúdo. O processo de análise envolveu o inter-relacionamento entre os relatos dos indivíduos sobre as rotinas de compra, os artefatos e as observações de campo, para entender se existiam aderências ou divergências.

Tabela 2

Fontes de evidências e descrição

\begin{tabular}{|c|c|}
\hline Fonte de entrevistas & Descrição \\
\hline Artefatos & $\begin{array}{l}\text { Organogramas, Fluxos de trabalho, Listagem de planejamento de compras, Fluxo paralelo de com- } \\
\text { pras, Matriz de problemas, Checklist de recebimento de material e nova Ficha de Especificação } \\
\text { de Produto, Regulamento de licitação de compras, Acordo de nível de serviço, Processo oficial de } \\
\text { compras, Norma administrativa de aquisição de bens e serviços, Instruções Operacionais de cada } \\
\text { etapa do processo de compras e Ficha de Especificação de Produto. }\end{array}$ \\
\hline Entrevistas & $\begin{array}{l}\text { Relatos, narrativas e depoimentos de } 18 \text { participantes de pesquisa, a partir de um relatório semies- } \\
\text { truturado. }\end{array}$ \\
\hline $\begin{array}{l}\text { Observações de } \\
\text { campo }\end{array}$ & $\begin{array}{l}\text { Experiência da compra e aspectos não verbais dos entrevistados, impressões das entrevistas, as- } \\
\text { pectos do ambiente de trabalho. }\end{array}$ \\
\hline
\end{tabular}




\subsection{TRATAMENTO DOS DADOS E PROCEDIMENTOS DE ANÁLISE}

As evidências coletadas na investigação incluem as transcrições das entrevistas, as observações da rotina de compras durante o período das entrevistas e documentos (artefatos). O material foi reunido e catalogado formando uma espécie de bibliografia comentada, de acordo com o seu tipo de conteúdo, conforme orienta Yin (2003), para uma triangulação das informações. Desse modo, o conteúdo foi lido e categorizado em blocos de informações que compuseram uma matriz de dados em Excel (Yin, 2003), a partir da qual a ideia geral resultante da análise foi comparada com os artefatos e observações do campo. Buscou-se entender as aderências ou divergências sobre as rotinas de compra, bem como o inter-relacionamento entre as evidências empíricas. Assim, a partir do processo de análise do material coletado, sustentado pela teoria utilizada no presente trabalho, foi possível identificar as categorias apresentadas na próxima seção que buscam explicar os fatores motivadores para as variações das rotinas estudadas, contribuindo com os objetivos declarados nesta pesquisa: preencher as lacunas reveladas no estado da arte da literatura de rotinas, pela perspectiva processual. Por último, foram verificadas e reanalisadas as congruências entre os achados e a teoria sobre as rotinas organizacionais. Esse procedimento forneceu suporte para as discussões e considerações finais.

\section{ANÁLISE DOS RESULTADOS}

Esta seção está organizada em duas subseções principais. A primeira descreve o caso estudado e apresenta a variação da rotina de compras identificada empiricamente e suas implicações teóricas e práticas. A segunda subdivide-se em quatro e apresenta as categorias descritivas dos fatores motivadores da variação das rotinas de compras de insumos na instituição estudada.

Esta pesquisa foi embasada em estudos sobre as rotinas organizacionais sob a perspectiva prática, adotada por Feldman e Pentland (2003), com suposição de que as rotinas podem ser internamente dinâmicas (Feldman, 2016), têm relações com os artefatos utilizados nas rotinas (Feldman, 2003) e são interdependentes (Spee et al., 2016; Feldman, 2016). Assim, buscou-se "abrir" as rotinas de compras de insumos químicos do caso aqui estudado para entender a dinâmica interna de rotinas interdependentes, e o papel dos artefatos utilizados tanto pelas equipes de compras quanto pela área técnica. Para tanto, identificaram-se as categorias reveladoras de motivos que promovem a variação das rotinas (Feldman, 2000, 2003, 2004; Feldman \& Pentland, 2003, 2008; Pentland \& Feldman, 2005, 2008; Howard-Grenville et al., 2016; Feldman et al., 2016; Sele \& Grand, 2016). 


\subsection{O CASO ESTUDADO}

\subsubsection{O Instituto "A"}

O Instituto "A" integra uma organização que, com mais de 60 anos no mercado, colabora para o desenvolvimento da indústria fluminense com a geração e a disseminação de conhecimento técnico e tecnológico, atuando com serviços de tecnologia e inovação ligados a análises e ensaios químicos. Em sua estrutura, entre suas unidades de negócios, existem outros três institutos de tecnologia que atuam provendo soluções para viabilizar processos industriais eficientes por meio de serviços de consultoria, metrologia e PD\&l (Pesquisa, Desenvolvimento e Inovação), baseados em diferentes áreas do conhecimento. Para operar, o Instituto "A" necessita de insumos químicos, que são incomuns: reagentes, diluentes e substâncias apresentadas em diferentes graus de pureza para serem utilizadas de acordo com o tipo de análise ou nível de confiança pretendido pelo cliente. Esses insumos podem exigir certificação e/ou autorização de órgãos específicos para uso. Além disso, a cadeia de fornecedores no Brasil é bastante restrita, sendo muito difícil reunir em um só fornecedor uma gama diversificada de insumos.'

Observa-se que esse caso não trata de apenas uma única rotina (restrita), mas da perspectiva de rotinas interdependentes que se afetam mutuamente (Feldman et al., 2016; Howard-Grenville et al., 2016). Em geral, os serviços de análises e ensaios atendem às exigências legais da indústria, controladas por órgãos ambientais que certificam, licenciam e chancelam a operação dentro de preceitos socioambientais legais, justificando a importância e a responsabilidade de prover serviços tecnológicos com a máxima eficiência, agilidade e rapidez. A demanda por esses serviços aumentou nos últimos anos, impelida pelo rigor das leis ambientais do Brasil, com contratos anuais de grandes empresas, além de demandas pulverizadas para um grande número de clientes.

À medida que a organização, na qual o Instituto "A" é integrante, gere dinheiro público, seus processos de compras são auditados por órgãos competentes e devem seguir as diretrizes do regulamento institucional de compras baseado na Lei n. 8.666 (1993): ${ }^{2}$ compras de valor acima de determinado montante devem ser realizadas por meio de licitação.

No entanto, há uma ressalva na Lei, pela qual compras de pequenos volumes ou insumos específicos "em caso de emergência" podem prescindir dessa licitação consistindo em as chamadas "aquisições diretas" (emergenciais), que devem acontecer somente mediante algumas circunstâncias e regras específicas ${ }^{3}$ as quais preconizam uma autorização do gestor e uma cotação com três fornecedores diferentes com regularidade fiscal.

Assim, compreende-se que a rotina original de compras que adquire insumos químicos para serem utilizados nas rotinas de análises e ensaios define que a área de compras (o Setor

\footnotetext{
Trabalham com químicos específicos (só sólidos, só líquidos, só controlados).

2 Lei n. 8.666, 1993. Lei Federal que rege o processo de compras de empresas públicas.

3 Em caso de emergência ou atendimento à situação que possa ocasionar prejuízo ou insegurança, ou em caso de urgência ou atendimento de situações imprevistas ou imprevisíveis para se realizar a licitação. Devem acontecer mediante autorização do gestor e ter cotação de preços em três fornecedores com regularidade fiscal.
} 
de Compras está indicado na Figura 1) é responsável por todas as compras da organização e deve executar atividades de: pesquisa de fornecedores, operação das compras "por licitação" e condução (registro/controle) do processo por meio do sistema corporativo Enterprise Resource Planning (ERP). Por sua vez, a área chamada de "técnica", cujos membros atuam na rotina de análises e ensaios, tem as responsabilidades de: realizar as análises e ensaios; manter atualizada a "Ficha de Especificação do Material" (que detalha a especificação técnica dos insumos químicos); e emitir as solicitações de compras.

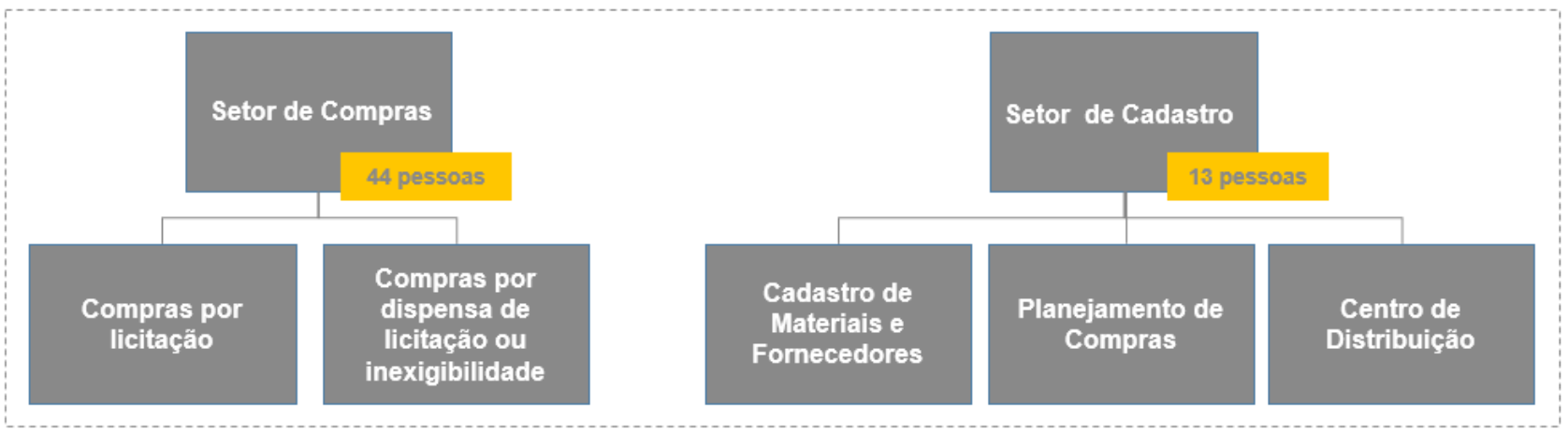

Figura 1. Estrutura do Setor de Compras

\subsubsection{AS VARIAÇÕES ENCONTRADAS NAS ROTINAS DE COMPRAS E EM ANÁLISES E ENSAIOS}

As rotinas estudadas no presente trabalho apresentam variações endógenas, como discorre a literatura sobre o tema (Feldman, 2003, 2016). Observou-se a existência de ostensivos contraditórios entre os envolvidos (Howard-Grenville \& Rerup, 2017), além do uso (e compreensão) divergente dos artefatos atrelados à ecologia das rotinas de compras e análises e ensaios (Pentland \& Feldman, 2005). É possível entender que a variação da rotina pode estar caminhando para se estabilizar, sem que a performance e os artefatos estejam realinhados, bem como sem que sejam percebidas manifestações de uma trégua que, conforme Salvato e Rerup (2017), indica uma cessão de disputas a qual pode evitar que as rotinas sejam conduzidas por interesses divergentes (Salvato \& Rerup, 2017). Além disso, como o contexto do Instituto "A" é altamente regulamentado, essa variação da rotina (com a inversão de responsabilidades e atividades) pode depender de reconhecimento por órgãos competentes.

Nessa variação observa-se que, a partir das interpretações do "Artefato-Lei", há tanto uma variação na atividade quanto uma inversão-chave dos responsáveis, ainda que o sistema corporativo para o registro das compras não tenha essa alternativa. Dessa forma, pode-se compreender que existem aspectos desfavoráveis, uma vez que se atesta a ineficiência dos processos internos, além de poder comprometer a eficiência da produtividade do Instituto "A" em sua atividade-fim, que se dedica às análises e aos ensaios clínicos.

As evidências dessa situação ilustram que, mesmo sendo a modalidade de compras "por licitação" preconizada e apoiada pela área de compras, há quatro ou cinco anos, a área de compras vem tendo dificuldade em prover um fluxo adequado de suprimentos de insumos químicos, 
fazendo compras incorretas, fora da especificidade, fora do prazo necessário, tendo em vista a alta demanda por serviços do laboratório e outros fatores como dificuldades técnicas. Assim, com base na cláusula "especial" da lei de "aquisição direta" ("casos de emergência", "situações de prejuízo ou insegurança", "situações imprevistas ou imprevisíveis para a licitação"), que dispensa o procedimento de licitação, as compras desse tipo de insumos químicos deixaram, gradativamente, de ser realizadas pela área de compras, conforme previsto na regra da "licitação" e passaram a ser realizadas pelos próprios técnicos do Instituto "A", uma vez que esse setor declara que precisa de itens emergenciais para suportar sua operação. Logo, a área técnica do Instituto "A" passou a realizar $89 \%$ das compras de materiais de seu consumo, por meio da compra de pequenos lotes, permanecendo a área de compras responsável, apenas, pela atividade de "fechamento" da compra (registro) no sistema corporativo.

Cabe ressaltar que, segundo Spee et al. (2016), habilidades e conhecimentos profissionais envolvidos na prática podem fazer com que as pressões de mudança em rotinas interseccionadas tendam para um ou outro ostensivo concorrente. No entanto, segundo os autores, há o risco de que um desvio profissional conduza para um lado extremo de um desses ostensivos concorrentes.

Dessa maneira, identificou-se que as áreas envolvidas no processo de aquisição e uso dos insumos químicos em análises e ensaios possuem alguns ostensivos contraditórios/ conflitantes. $O$ novo padrão de ação tem se repetido, mas permanece a necessidade de que a performance e os artefatos sejam realinhados, assim como persistem as questões da frequente/crescente solicitação à aprovação da gerência técnica e a necessidade de anvência externa (auditorias e área de processos). Ademais, ainda que o termo não seja absoluto (Pentland \& Feldman, 2005), a carência de trégua no caso estudado pode ser compreendida pela não observação de manifestações desse fenômeno, conforme apontado na literatura recente. Tendo em vista o caráter generativo das rotinas, é possível concluir que as mudanças devem continuar se sucedendo. Dessa forma, a trégua pode ser desenvolvida (revisitada) no processo de aprendizado, adaptação e questionamentos sobre como será a performance futura, que ocorre na dinâmica da performance contínua (Zbaracki \& Bergen, 2010, p. 967).

\subsection{OS FATORES MOTIVADORES DAS VARIAÇÕES NAS ROTINAS DE COMPRAS}

Quatro categorias de análise dos resultados representam os fatores que motivam as variações na performance da rotina de compras de insumos do Instituto "A".

\subsubsection{Compreensão de papéis e interesses}

A análise do conteúdo das entrevistas aponta elementos sugestivos de que o conhecimento abstrato da rotina, o aspecto ostensivo (Pentland \& Feldman, 2005), pode estar com diferentes percepções entre os participantes das rotinas de compras e os participantes que realizam as análises químicas (os técnicos) e, ainda, as pessoas da área de processos. A esse respeito, foi apontado 
na entrevista Pl que "[. . .] não existe uma matriz de responsabilidade clara [...] as funções se sobrepõem." (informação verbal).

Por tais entendimentos distintos, a área técnica precisou incorporar a prática da compra de insumos químicos para obter melhor viabilidade para seus serviços de ensaios e análises, ainda que a área de compras possuísse, formalmente, o papel de realizar as compras corporativas, dentro dos preceitos legais. Assim, o desvio dessa função, seja pela troca de papel, seja por estar fora da legalidade estabelecida, pode ser caracterizado como uma variação da rotina (Feldman, 2000, 2003; Feldman et al., 2016).

Identificou-se, também, uma divergência na compreensão dos interesses: por um lado, os entrevistados do setor de compras afirmaram que as licitações precisam ser planejadas para grandes volumes, com antecedência mínima de seis meses. Por outro lado, a área de processos considera que, visto que suas necessidades eram, de certa forma, urgentes, a área de compras estava muito atrelada às questões legais, não conseguindo, assim, cumprir um papel de parceira de outras áreas, fundamentando a ideia do atributo automático ligado à rotina e da concepção de irracionalidade (Nelson \& Winter, 1982; Feldman, 2000, 2003). Da mesma forma, a área técnica observou a falta de parceria da área de compras:

Eu acho que a estrutura [da área de compras] que, às vezes, pode não estar de forma adequada para nos atender na velocidade que nós precisamos [. . .] (Entrevista T4).

... tem que entender a angústia de quem está na ponta, de cara para o cliente .... área de compras é muito focada em compras de rotina, e não alinhada de fato com todo o plano estratégico, com suas ações e com seus projetos. (Entrevista P1) (informações verbais).

Assim, as diferentes interpretações do artefato-lei (Lei n. 8.666) impactam também as atividades de planejamento das áreas. Enquanto a área de compras preconiza o critério da Lei (com rigor) no qual é a sua área que faz a compra "por licitação" e também o registro do estoque no sistema corporativo (as compras por pequenos lotes seriam extraordinárias), a área técnica requer compras em quantidades menores, rápidas, que não justificam o volume para abrir um processo licitatório e, ainda, que podem evitar perdas financeiras decorrentes de descarte de insumos por prazo de validade vencido. Além disso, existem declarações divergentes sobre a necessidade da atividade do planejamento, que também afeta a interface entre as duas rotinas interdependentes:

Se a área de compras pretende esperar juntar 44 mil em reagentes para abrir um processo de licitação e comprar de uma única vez, mesmo para uma previsão de seis meses, teria que juntar muito, muito (Entrevista T2).

... a área de compras deve fazer as cotações para efetivar a compra e a área técnica deve fazer a cotação apenas para a evidência de preço . . . há uma confusão mental da área solicitante . . . cotar preço é o trabalho do comprador . . . . Se a área técnica não fizer as cotações, a compradora vai precisar de uma semana a 10 dias para fazer a cotação ... . não por ela ser lenta, mas o mercado demora ... (Entrevista C1). Eu afirmo para você: se houver planejamento, a compra funciona ... . Há dois anos nós da área de compras implantamos as visitas técnicas, que servem para concentrarmos as demandas, abrindo os procedimentos de licitação. Se o Instituto "A" não tem planejamento ou não quer entrar em um procedimento licitatório, que é mais pesado, então eles compram para fugir disso. (Entrevista C2).

Ainda não notei diferença alguma com as visitas técnicas para planejamento, porque a maior parte das unidades alega que não tem como prever a demanda. (Entrevista C3) (informações verbais). 
Diante do exposto sobre os interesses preconizados nas rotinas de compras e rotinas de análises e ensaios, percebeu-se que existe uma falta de unicidade na forma como as duas áreas interpretam o objetivo de periodicidade de compras de insumos químicos, evidenciando a afirmação de Pentland e Feldman (2005) sobre divergências na compreensão de um padrão abstrato (o aspecto ostensivo) a partir de diferentes pessoas e/ou em diferentes momentos.

Ainda em relação à compreensão de papéis, os entrevistados podem divergir sobre as competências necessárias para realizar as atividades: "[. . .] esta compra é muito complexa até para um químico." (Entrevista T2) (informação verbal).

... para nós é muito difícil comprar, somos uma organização privada, mas com processos quase que públicos. Somos obrigados a cumprir determinadas rotinas que constam nas licitações . . . a gente tem um profissional de compras dedicado ao Instituto "A" ... (Entrevista C1).

Nossos compradores têm noções, muitas noções de materiais. Se não conhecerem o material eles não seriam compradores. A ficha de especificação é só detalhe. Nossos compradores compram para a empresa como um todo. Não há um comprador específico para cada segmento de produto ou unidade de negócios. (Entrevista C2).

Já tem o costume de comprar um determinado material. Eles [compradores] já até sabem se a especificação do produto está correta ou não e, ainda, . . . e é o mercado que vai acusar qualquer erro ou inconsistência. (Entrevista C3) (informações verbais).

A Tabela 3 resume as divergências entre os entendimentos das áreas e os resultados da análise dessa categoria:

Tabela 3

Resumo de entendimentos e resultados

\begin{tabular}{lll}
\hline $\begin{array}{l}\text { Entendimentos sobre o alinhamento de } \\
\text { papéis, conceitos e interesses }\end{array}$ & Relatos e resultados encontrados & Área Técnica \\
\cline { 2 - 3 } Papel da área de Compras & Defender a empresa nas auditorias. & $\begin{array}{l}\text { Deveria ser de parceria, mas não há } \\
\text { como defender a área de compras. }\end{array}$ \\
\hline $\begin{array}{l}\text { Conceito de compra de insumos quími- } \\
\text { cos }\end{array}$ & $\begin{array}{l}\text { Atores estratégicos consideram as } \\
\text { compras indiferentes e atores táticos e } \\
\text { operacionais consideram-nas específ- } \\
\text { cas e difíceis. }\end{array}$ & $\begin{array}{l}\text { Específica, difícil, peculiar e totalmen- } \\
\text { te diferente de qualquer compra da } \\
\text { empresa. }\end{array}$ \\
\hline $\begin{array}{l}\text { Interesses das áreas em relação à com- } \\
\text { pra de insumos químicos }\end{array}$ & $\begin{array}{l}\text { Cumprir os requisitos legais da compra } \\
\text { é a prioridade. }\end{array}$ & $\begin{array}{l}\text { Ter processos ágeis que garantam o } \\
\text { suprimento para projetos urgentes é } \\
\text { prioridade. }\end{array}$ \\
\hline Rotinas organizacionais de compras & $\begin{array}{l}\text { Adequadas perante a auditoria. } \\
\text { Inadequadas para cumprir os prazos } \\
\text { que os clientes internos necessitam. }\end{array}$ & $\begin{array}{l}\text { Ineficientes, engessadas e não pro- } \\
\text { veem a necessidade da área técnica. }\end{array}$ \\
\hline
\end{tabular}

Portanto, pode-se depreender que pessoas que realizam rotinas interdependentes e que atuam em áreas diferentes podem divergir sobre seus papéis e sobre a forma como compreendem as rotinas em si, ao mesmo tempo que podem buscar interesses particulares de sua área, quando se motivam para modificar as rotinas. Dessa forma, para que essas variações sejam bem-sucedidas para a organização, pode ser relevante contemplar a questão comportamental para buscar esse realinhamento de interesses pela organização. A frequência nas variações das sequências em recorrentes interações de padrões de ação pode vir a construir tréguas e previsibilidade do comportamento dos demais, podendo facilitar a coordenação de atividades (Becker, 2005). 
Howard-Grenville e Rerup (2017) alegam que, tendo em vista a questão tácita e subjetiva do entendimento sobre as rotinas, o aspecto ostensivo das rotinas e os artefatos podem divergir, mas podem influenciar na dinâmica das rotinas (Cacciatori, 2012; Howard-Grenville \& Rerup, 2017). A próxima categoria evidencia como os artefatos podem moldar as rotinas estudadas (HowardGrenville \& Rerup, 2017).

\subsubsection{O papel dos artefatos}

Outro ponto de partida para provocar mudança ou adaptações nos padrões da rotina de compras pode estar relacionado aos artefatos: (a) Lei; (b) Ficha de Especificação do Material; e (c) sistema corporativo tecnológico (ERP). Esses artefatos, segundo a tipologia de Cacciatori (2012), podem ser considerados como "falantes" e "específicos da ocupação". Segundo a autora, os artefatos "falantes" podem mediar os esforços dos envolvidos para o endereçamento de soluções de problemas, enquanto a natureza dos artefatos "específicos da ocupação", que são essenciais para o desempenho da atividade, tornam-os críticos na questão entre o conflito e a resolução de problemas. Assim, observa-se que os artefatos usados nas rotinas interdependentes estudadas no presente trabalho embutem conhecimento à semelhança da proposição de Cacciatori (2012). Destaca-se que o conteúdo do artefato (b) Ficha de Especificação do Material pode ser considerado como essencial para o desempenho da atividade de compras de insumos, bem como os artefatos (a) Lei e (c) sistema visam tanto a orientar quanto a restringir a ação nas rotinas.

No que diz respeito à legislação, a categoria "Compreensão de papéis e interesses" ilustrou como o Artefato-Lei (Lei n. 8.666) gera desentendimentos em razão da existência da cláusula de ressalva sobre as compras emergenciais.

A Ficha de Especificação do Material também é outro artefato relevante cuja interpretação de sua utilidade diverge entre os entrevistados:

\footnotetext{
A especificação do material é a alma do negócio ... . e se estiver malfeita faz com que a gente ou compre mal, ou compre errado. As informações colocadas na ficha são "pífias" ou sequer informam alguma coisa . ... são um problema sério, muito sério .... Este artefato é satisfatório para a realização da compra, pois foi melhorado recentemente. (Entrevista C1).

Essa ficha de produto não é dinâmica, não é atualizada, não tem mudança, pois a equipe de compras não tem capacidade técnica para fazer a atualização e a gente tem que fazer a toda hora uma ficha de produto para algum produto que já está cadastrado, mas com uma outra especificação de embalagem. (Entrevista T6) (informações verbais).
}

Por meio da observação empírica e dos relatos, notou-se que as embalagens dos fornecedores variam muito, principalmente para os insumos importados de vários países. Por exemplo, álcool 99\% 250 mL, álcool 99\% 500 mL, álcool 99\% 1000 mL e álcool 99\% 1 L são cadastros diferentes usados para fins de cálculo automático: "Se coloco em Kg e o produto está em grama, dá erro ... . um reagente de 24 mil custava R\$192. O sistema não tem um campo onde a gente possa anotar nada, nem posso inserir nada." (Entrevista C8) (informação verbal). 
O sistema (tecnológico) de compras atual também permanece com desalinhamento com o novo padrão de ação da predominância de compra como emergenciais. O sistema prevê que compras diretas (sem licitação) são parametrizadas como não estocáveis, independente da perecibilidade. Por isso, o histórico das compras emergenciais não é preservado. Esse aspecto do "não registro via estoque" e o uso intensivo de processos manuais/carimbos/validações físicas nas rotinas não contemplam as facilidades que poderiam ser geradas por novos processos informatizados (Pentland \& Haerem, 2015; Leonardi, Nardi, \& Kallinikos, 2012).

Há também uma "variação" performativa na forma do uso do artefato tecnológico: o sistema corporativo Enterprise Resource Planning (ERP) está sendo utilizado pelo próprio setor de compras somente em um momento posterior às etapas da compra, no fechamento. Tal ocorrência, inclusive, reforça a acepção sobre variações relacionadas com a forma pela qual os indivíduos interpretam o uso dos artefatos tecnológicos, pois, segundo Orlikowski (1992), "[. . .] mesmo a tecnologia mais "caixa-preta" precisa ser apreendida e aceita pelo agente humano para ser eficaz" (p. 402).

As variações do uso do artefato configuram uma das correntes explicadas por D'Adderio (2008), na qual, em vez de os artefatos terem poder de definir um "enquadramento" para as ações, há um "transbordamento" delas, com agentes humanos capazes de interpretar, modificar e, em alguns casos, substituir totalmente uma regra ou procedimento.

Reconhece-se nos achados desta pesquisa a necessidade de rediscutir e reconfigurar os artefatos existentes nas rotinas de compras, assim como Cacciatori (2012) alega que as modificações de sistemas mediam as fronteiras entre conhecimentos interdependentes, podendo sustentar um novo padrão de ação de resolução de problemas e uma nova trégua na forma como o trabalho será divido. Assim, há de se concordar com a afirmação de que: "[. . .] o tipo de trégua que esses sistemas [de artefatos] incorporam se torna relevante para determinar se uma nova rotina emerge ou não." (Cacciatori, 2012, p. 1578).

\subsubsection{Relação entre os aspectos ostensivo, performativo e artefatos}

Embora a inter-relação entre as rotinas de análises clínicas e a rotina de compras para aquisição dos insumos químicos pode ser explicada pelo argumento de Kremser e Schreyögg (2016), de que uma rotina complexa se divide por meio de duas ou mais rotinas especializadas, nas quais uma depende da outra, verificou-se que as ações das rotinas estão dispostas em silos, sem uma coordenação entre as atividades performadas por cada área e entre os múltiplos atores (Pentland \& Feldman, 2008a). Desse modo, os artefatos não descrevem nem intermedeiam as adaptações que já configuram um novo padrão de ação (emergent accomplishment) (Pentland \& Feldman, 2005; Feldman, 2016).

Há quem entenda que a nova performance produz resultados positivos, que poderiam ser incorporados à rotina oficial, considerando que o ostensivo não restringiu o performativo e que a fonte de mudança está na agência do sujeito (Feldman, 2000, 2003; D'Adderio, 2008). Por um lado, o performativo recriou a rotina a partir de um ostensivo da área técnica, mais rápido e ágil para 
as compras. Por outro lado, os artefatos não acompanham os aspectos ostensivo e performativo, permanecendo defasados em relação ao contexto (Gersick \& Hackman, 1990; Pentland \& Feldman, 2008b). Além disso, precisa-se alcançar alguma nova trégua, que configure o que Nelson e Winter (1982) chamaram de "estado de alerta", no qual a rotina reconhece os interesses dos membros da organização. Além disso, Cacciatori (2012) reforça que artefatos classificados como "falantes" e "específicos da ocupação" são relevantes na codificação de "quem" e "como" se usam os conhecimentos específicos e na resolução de problemas e conflitos.

A Tabela 4 apresenta um resumo sobre a relação entre os aspectos da rotina e seus artefatos, evidenciando a falta de dinamismo necessário para a mudança:

Tabela 4

Interações e dinâmica das relações

\begin{tabular}{|c|c|}
\hline Interações & Resultado da Dinâmica das Relações \\
\hline $\begin{array}{l}\text { Ostensivo-Per- } \\
\text { formativo }\end{array}$ & $\begin{array}{l}\text { - Ostensivo permanece inflexível (licitações), desconsiderando as peculiaridades da compra de que quí- } \\
\text { micos e elementos exógenos indiquem a necessidade de mudança. } \\
\text { - Performativo varia a partir das ações da equipe técnica, com a inversão de algumas etapas do ostensi- } \\
\text { vo e o desempenho de ações que não estão suportadas por ele. }\end{array}$ \\
\hline $\begin{array}{l}\text { Artefatos-Per- } \\
\text { formativo }\end{array}$ & $\begin{array}{l}\text { - Performativo sofre adaptação e melhorias que não são incorporadas no artefato sistema. Há empode- } \\
\text { ramento da área técnica para a alteração da performance justificada pela necessidade de atender o } \\
\text { cliente. A área de compras é controlada por artefatos. } \\
\text { - Artefatos continuam estáticos, sem apoiar o novo padrão de ação das performances da compra. As } \\
\text { informações sobre as compras não são registradas adequadamente. }\end{array}$ \\
\hline $\begin{array}{l}\text { Artefatos-Os- } \\
\text { tensivo }\end{array}$ & $\begin{array}{l}\text { - Ostensivo com desalinhamento entre áreas. O processo centralizado de compras desconsidera as com- } \\
\text { pras que não seguem padrões tradicionais. } \\
\text { - Artefatos alinhados para cumprir regras em detrimento de outras necessidades. Ausência e inadequa- } \\
\text { ção de artefatos. }\end{array}$ \\
\hline
\end{tabular}

No presente trabalho aponta-se para a busca de um realinhamento entre a performance da rotina e a compreensão dos papéis e interesses, e a revisão dos artefatos. Além disso, a dinâmica das rotinas precisa prosseguir até o alcance de um objetivo comum, ocorrendo uma trégua entre os envolvidos, com consenso e colaboração mútua (Salvato \& Rerup, 2017), favorável não apenas à produtividade das áreas envolvidas, mas também em condições de ser reconhecido na organização e por órgãos competentes externos.

A questão estrutural e externa é comentada na próxima categoria, que aborda as influências de fatores contingenciais nas rotinas.

\subsubsection{Fatores contingenciais na dinâmica das rotinas}

As entrevistas e a observação no campo também evidenciaram algumas influências de fatores exógenos, como a mudança dinâmica nas especificações dos insumos químicos, o aumento da demanda e o comportamento da cadeia de fornecedores.

Parece que a variação da rotina de compras que inverte as responsabilidades e a forma como são realizadas as atividades emergiu para alcançar a velocidade esperada para atender ao mercado, que é crescente. As novas práticas adotadas dentro desse contexto material e social ganharam um caráter de interdependência que não havia na rotina original, formando uma rede 
de participantes ativos, implicando a efetivação da rotina e respeitando os interesses dos partícipes (Pentland \& Haerem, 2015). A Tabela 5 apresenta o rol de variações e impactos por tipo:

Tabela 5

Variações das rotinas, impactos e tratamento

\begin{tabular}{lll}
\hline N. & \multicolumn{1}{c}{ Variação da rotina organizacional } & \multicolumn{1}{c}{ Impacto } \\
\hline & $\begin{array}{l}\text { Performance realizada pelo ator indevido (compra, re- } \\
\text { cebimento das mercadorias, cotação e evidência de } \\
\text { preços feitos pela área técnica). }\end{array}$ & $\begin{array}{l}\text { Perda de produtividade da área técnica e risco organi- } \\
\text { zacional; procedimento de vistoria pode ser desconside- } \\
\text { rado; estocagem inexistente. }\end{array}$ \\
2 & $\begin{array}{l}\text { Inversão de etapas da rotina de compras } \\
\text { Rapidez no processo de compra emergencial. }\end{array}$ \\
& $\begin{array}{l}\text { Descumprimento de etapas-chave das rotinas (compras } \\
\text { de insumos não são registradas como estoque). }\end{array}$ & $\begin{array}{l}\text { Não gera banco de dados útil para planejamento; regis- } \\
\text { tro sobre estoque no sistema deficitário. }\end{array}$ \\
& $\begin{array}{l}\text { Algumas performances são realizadas, mas não existe } \\
\text { um aspecto ostensivo que as suporte (negociação da }\end{array}$ & $\begin{array}{l}\text { Inicialmente o impacto é positivo, pois efetiva a compra } \\
\text { (rapidez na resposta do fornecedor, cotações e monito- } \\
\text { entrega com o fornecedor, qualificação de fornecedo- } \\
\text { ramento da entrega do produto. Porém, não há envolvi- } \\
\text { res e acompanhamento de pedido). }\end{array}$ \\
\hline
\end{tabular}

Assim, a razão para a variação da rotina também emerge quando se considera a estrutura das rotinas de compra, totalmente baseada na aquisição de produtos padronizados, comuns, com volumes maiores e estocáveis, cuja cadeia de fornecedores é ampla e conhecida. O objetivo proposto por essa estrutura é o cumprimento da modalidade de licitação nas compras, o que contradiz as necessidades apontadas para a compra de insumos químicos.

A esse respeito, julga-se oportuno considerar que o alcance de uma futura fase de estabilidade das rotinas estudadas pode vir a ocorrer mediante a identificação de manifestações de trégua sugeridas pela literatura como: compreensão dos objetivos uns dos outros; colaboração entre os envolvidos; disponibilidade (vontade) para fazer concessões; e acomodação de tensões (Zbaracki \& Bergen, 2010; Salvato \& Rerup, 2017) ou iniciativas de mudança cognitiva e motivacional para sair da inércia (Kaplan, 2015).

Além disso, a discussão sobre a influência estrutural na busca de estabilização de rotinas interdependentes e de maneiras de se (re)estabelecer tréguas entre elas pode ser observada por Zbaracki e Bergen (2010). Adicionalmente, Salvato e Rerup (2017) destacaram ações de workshops e atenção do Chief Organizational Officer (CEO) como facilitadoras de realinhamento de objetivos entre indivíduos que atuam em distintas rotinas organizacionais. De forma semelhante, Kaplan (2015) aponta o papel do CEO na mobilização da equipe de apoio a fim de fornecer sustentações cognitivas e motivacionais para "quebrar" e "restabelecer" novas rotinas (sair da inércia).

\section{CONSIDERAÇÕES FINAIS}

Neste trabalho buscou-se entender as relações e influências mútuas entre as rotinas de compra de insumos químicos e as rotinas de análise e ensaios de um Instituto de Tecnologia e Inovação, com foco na dinâmica interna de rotinas interdependentes, bem como sobre o papel dos artefatos nessa dinâmica.

Os achados da pesquisa denotam certa convergência entre os resultados encontrados e os pressupostos teóricos de Feldman e Pentland. Demonstram, também, o poder do agente na modificação da rotina, mas também a relação de interdependência entre rotinas, assim como a 
influência dos artefatos na recursividade entre os aspectos ostensivo e performativo. Observa-se que, apesar de a nova performance poder produzir um resultado aderente ao pretendido e gerar inovação no processo para atender melhor à demanda, cabe o esforço por manter os padrões preconizados pelo regulamento interno de compras e a idoneidade das aquisições.

Acredita-se que, tanto para a gestão da organização quanto para os atores envolvidos, este trabalho oferece elementos para uma autorreflexão fundamental no sentido de avaliar a necessidade de tornar as variações das rotinas ao contexto do negócio e à situação como válidas e reconhecíveis por todos os envolvidos.

O presente trabalho contribui com a teoria sobre a dinâmica das rotinas. Primeiramente, evidencia a existência de uma dinâmica interna das rotinas, que abarca também rotinas interdependentes, endossando a afirmação de Sele e Grand (2016) sobre o fato de que todos os atores possuem potencial para uma agência generativa (modificar ou criar rotinas).

Em segunda instância, é possível compreender que a presente investigação desperta novas reflexões sobre a natureza da trégua em rotinas múltiplas e como sustentam seu caráter generativo em ostensivos contraditórios. Mesmo que a trégua não "elimine" conflitos, mantendo-os latentes, e que o termo "trégua" possa ser relativo, é possível entender que a estabilidade da nova rotina depende de manifestações de trégua, conforme vem sendo conceituado na literatura. Assim, conforme Cacciatori (2012), a modificação dos artefatos deve considerar o que é passível de ser cumprido e também se relacionar com uma "trégua aceitável" sobre o trabalho nas rotinas.

Ademais, as categorias identificadas denotam as razões para as quais ocorre o "despertar" do potencial endógeno generativo para a mudança da rotina, na situação em que as rotinas não estão atendendo à demanda de seus clientes internos ou externos. Assim, o trabalho contribui, também, com reflexões sobre como a dinâmica interna das rotinas pode "continuar" a insistir que seus artefatos sejam revistos, atualizados e, assim, adotados na prática das rotinas interligadas efetivamente, além do reconhecimento organizacional. Nesse sentido, esta pesquisa pode sugerir que novas investigações tenham foco nas variadas formas pelas quais pode ocorrer trégua em rotinas interdependentes.

O trabalho limita-se ao tipo específico de rotinas de compras, com características sobre as regulamentações em que o Instituto "A" atua. Para futuras pesquisas, pode-se aprofundar a problematização da variação em rotinas organizacionais, aprofundando o papel dos artefatos tecnológicos, como o exemplo do sistema Entreprise Resource Planning (ERP), entrelaçados com as rotinas de compras, enquanto instrumento de trabalho e controle do fluxo das informações e definição de responsabilidades.

\section{REFERÊNCIAS}

Becker, M. C. (2005). A framework for applying organizational routines in empirical research: Linking antecedents, characteristics and performance outcomes of recurrent interaction patterns. Industrial and Corporate Change, 14(5), 817-846. 
Cacciatori, E. (2012). Resolving conflict in problem-solving: Systems of artefacts in the development of new routines. Journal of Management Studies, 49(8), 1559-1585.

Cherman, A., \& da Rocha-Pinto, S. R. (2016). Valoração do conhecimento nas organizações e sua incorporação nas práticas e rotinas organizacionais. Revista Brasileira de Gestão de Negócios, $18(61)$.

D'Adderio, L. (2008). The performativity of routines: Theorising the influence of artefacts and distributed agencies on routines dynamics. Research Policy, 37(5), 769-789.

Dosi, G., Nelson, R., \& Winter, S. (2000). The nature and dynamics of organizational capabilities. Oxford, United Kingdom: OUP Oxford.

Feldman, M. S. (2003). A performative perspective on stability and change in organizational routines. Industrial and corporate change, 12 (4), 727-752.

Feldman, M. S., \& Orlikowski, W. J. (2011). Theorizing Practice and Practicing Theory. Organization Science, $22(5), 1240-1253$.

Feldman, M. S., \& Pentland, B. T. (2003). Reconceptualizing Organizational Routines as a Source of Flexibility and Change. Administrative Science Quarterly, 48(1), 94-118.

Feldman, M. S., \& Pentland, B. T. (2008). Routine dynamics. In D. Barry, \& H. Hansen (Eds.), The SAGE handbook of new approaches in management and organization. United Kingdom: Sage.

Feldman, M. S. (2000). Organizational routines as a source of continuous change. Organization science, $11(6), 611-629$.

Feldman, M. S., Pentland, B. T., D'Adderio, L., \& Lazaric, N. (2016). Beyond routines as things: Introduction to the special issue on routine dynamics. Organization Science, (3), 505-513.

Feldman, M. S. (2004). Resources in Emerging Structures and Processes of Change. Organization Science, 15(3), 295-309.

Feldman, M. S. (2016). Routines as process: Past, present, and future. In J. Howard-Grenville, C. Rerup, A Langley, \& Tsoukas (Eds.), Organizational Routines: How They Are Created, Maintained, and Changed. Oxford University Press, 23-46.

Gersick, C. J., \& Hackman, J. R. (1990). Habitual routines in task-performing groups. Organizational behavior and human decision processes, 47(1), 65-97. 
Howard-Grenville, J., A. \& Rerup, C. (2017). A process perspective on organizational routines. The SAGE Handbook of Process Organization Studies, 323-340.

Howard-Grenville. J. A., Rerup, C., Langley, A., \& Tsoukas, H. (2016) Introduction: Advancing a Process Perspective on Routines by Zooming Out and Zooming In J. Howard-Grenville, C. Rerup, A. Langley, \& H. Tsoukas (Eds.), Organizational Routines: How They Are Created, Maintained, and Changed, 5, 1-22.

Howard-Grenville, J. A. (2005). The persistence of flexible organizational routines: The role of agency and organizational context. Organization science, 16(6), 618-636.

Kaplan, S. (2015). Truce breaking and remaking: The CEO's role in changing organizational routines. Cognition and strategy, 1-45.

Kremser, W., \& Schreyögg, G. (2016). The dynamics of interrelated routines: Introducing the cluster level. Organization Science, $27(3)$, 698-721.

Leonardi, P. M., Nardi, B. A., \& Kallinikos, J. (Eds.). (2012). Materiality and organizing: Social interaction in a technological world. Oxford, United Kingdom: Oxford University Press on Demand.

Miller, K. D., Pentland, B. T., \& Choi, S. (2012). Dynamics of performing and remembering organizational routines. Journal of Management Studies, 49(8), 1536-1558.

Nascimento, C. A. X., Ruas, L. R., \& Silva, D. da (2017). Rotinas Organizacionais No Ambiente Da Teoria Evolucionária. Revista Ibero Americana de Estratégia, 16(3), 143-159.

Nelson, R. R., \& Winter, S. G. (1982). An evolutionary theory of economic change. Cambridge, Massachusetts, United States: Harvard University Press.

Nelson, R. R., \& Winter, S. G. (2002). Evolutionary theorizing in economics. Journal of Economic Perspectives, 16(2), 23-46.

Orlikowski, W. J. (1992). The duality of technology: Rethinking the concept of technology in organizations. Organization science, 3(3), 398-427.

Parmigiani, A., \& Howard-Grenville, J. (2011); Routines Revisited: Exploring the Capabilities and Practice Perspectives. Academy of Management Annals, 5(1), 413-453.

Pentland, B. T., \& Feldman, M. S. (2008a). Designing routines: On the folly of designing artifacts, while hoping for patterns of action. Information and organization, 18(4), 235-250. 
Pentland, B. T., \& Feldman, M. S. (2008b). 13 Issues in empirical field studies of organizational routines 1. Handbook of organizational routines, 281.

Pentland, B. T., \& Feldman, M. S. (2005). Organizational routines as a unit of analysis. Industrial and corporate change, 14(5), 793-815.

Pentland, B. T., \& Haerem, T. (2015). Organizational routines as patterns of action: Implications for organizational behavior. Annual Review of Organizational Psychology and Organization Behavior, 2(1), 465-487.

Pentland, B. T. (2003). Sequential variety in work processes. Organization Science, 14 (5), 528-540.

Remenyi, D., Williams, B., Money, A., \& Swartz, E. (1998). Doing research in business and management: An introduction to process and method. United Kingdom: Sage.

Rerup, C., \& Feldman, M. S. (2011). Routines as a source of change in organizational schemata: The role of trial-and-error learning. Academy of Management Journal, 54 (3), 577-610.

Sele, K., \& Grand, S. (2016). Unpacking the dynamics of ecologies of routines: Mediators and their generative effects in routine interactions. Organization Science, 27(3), 722-738.

Salvato, C., \& Rerup, C. (2017). Routine regulation: Balancing conflicting goals in organizational routines. Administrative Science Quarterly, 63(1), 170-209.

Spee, P., Jarzabkowski, P., \& Smets, M. (2016). The influence of routine interdependence and skillful accomplishment on the coordination of standardizing and customizing. Organization Science, 27(3), 759-781.

Turner, S. F., \& Rindova, V. (2012). A balancing act: How organizations pursue consistency in routine functioning in the face of ongoing change. Organization Science, 23(1), 24-46.

Yin, R. K. (2003). Estudo de Caso: Planejamento e Métodos. (2a ed.). Porto Alegre: Bookman.

Zbaracki, M. J., \& Bergen, M. (2010). When truces collapse: A longitudinal study of price-adjustment routines. Organization Science, 21 (5), 955-972. 


\section{Como citar este artigo:}

ABNT

PERFEITO, Florence Vidal; BROMAN Samantha Luiza de Souza; ROCHA-PINTO, Sandra Regina da. Variações nas rotinas de um Instituto de Tecnologia e Inovação: adaptações ao contexto e (re) alinhamento de interesses. RACE, Revista de Administração, Contabilidade e Economia, Joaçaba: Ed. Unoesc, v. 17, n. 3, p. 927-950, set./dez. 2018. Disponível em: <http://editora.unoesc.edu.br/index.php/race>. Acesso em: dia/mês/ano.

\section{APA}

Perfeito, F. V., Broman, S. L. de S., \& Rocha-Pinto, S. R. da. (2018). Variações nas rotinas de um Instituto de Tecnologia e Inovação: adaptações ao contexto e (re)alinhamento de interesses. RACE, Revista de Administração, Contabilidade e Economia, 17(3), 927-950. Retirado de http:// editora.unoesc.edu.br/index.php/race 